\title{
Is the DeVries-Rose to Weber Transition Empirically Possible with Sine-Wave Gratings?
}

\author{
Miguel A. García-Pérez \\ Universidad Complutense de Madrid
}

\begin{abstract}
Visual functioning at various retinal illuminance levels is usually measured either by determining grating acuity as a function of light level or by determining how sensitivity to sine-wave gratings changes with retinal illuminance. The former line of research has shown that grating acuity follows a two-branch relationship with retinal illuminance, with the point of discontinuity occurring at the transition from scotopic to photopic vision. Results of the latter line of research have summarily been described as a transition from the DeVries-Rose law to Weber's law, according to which log sensitivity increases linearly with log illuminance with a slope of 0.5 over a range of low illuminances (the DeVries-Rose range) and then levels off and does not increase with further increases of illuminance (the Weber range). This paper aims at determining the compatibility of the results of these two lines of research. We consider empirical constraints from data bearing on the shape of the surface describing contrast sensitivity to sine-wave gratings as a function of spatial frequency and illuminance simultaneously, in order to determine whether they are consistent with a summary description in terms of DeVries-Rose and Weber's laws. Our analysis indicates that, with sine-wave gratings, the DeVries-Rose law can only hold empirically at low spatial frequencies.

Keywords: Weber's law, DeVries-Rose law, contrast sensitivity, retinal illuminance, visual acuity
\end{abstract}

Con frecuencia se ha medido la función visual a distintos niveles de iluminancia, bien determinando la agudeza visual para enrejados sinusoidales en función del nivel luminoso o bien determinando la forma en que la sensibilidad a enrejados sinusoidales cambia con la iluminancia. La primera vía de acercamiento ha revelado que la agudeza varía con la iluminancia de acuerdo con una función de dos ramas y un punto de discontinuidad en la transicion de visión escotópica a visión fotópica. Los resultados obtenidos a través de la segunda vía se han resumido aludiendo a una transición de la ley de DeVries-Rose a la de Weber, según la cual el logaritmo de la sensibilidad aumenta linealmente con pendiente 0.5 a medida que aumenta la iluminancia (para niveles bajos de iluminancia que comprenden el llamado rango de DeVries-Rose) pero luego permanece constante e invariante ante sucesivos incrementos de iluminancia (dentro del llamado rango de Weber). Aquí se evalúa la compatibilidad de los resultados obtenidos en estas dos líneas de investigación. Se parte de las restricciones empíricas impuestas por datos que revelan la forma de la superficie de sensibilidad a enrejados sinusoidales en función de la frecuencia espacial y la iluminancia, y se determina si esas restricciones son compatibles con la descripción que ofrecen las leyes de DeVries-Rose y Weber. El análisis muestra que la ley de DeVries-Rose sólo es posible empíricamente para enrejados sinusoidales de baja frecuencia.

Palabras clave: ley de Weber, ley de DeVries-Rose, sensibilidad al contraste, iluminancia retiniana, agudeza visual

Address correspondence to: Miguel A. García-Pérez, Departamento de Metodología, Facultad de Psicología, Universidad Complutense, Campus de Somosaguas, 28223 Madrid ( Spain). Phone: +34 913943 061. Fax: +34913943 189. E-mail: miguel@psi.ucm.es 
The relationship between retinal illuminance and contrast sensitivity to sine-wave gratings is summarily described as obeying DeVries-Rose and Weber's laws (Graham, 1989, Section 13.9.1; Shapley \& Enroth-Cugell, 1984): At low illuminance, sensitivity increases with the square root of illuminance (over the so-called DeVries-Rose range) and then becomes constant and independent of illuminance (over the so-called Weber range). Also, with the exception of high spatial frequencies - which do not show a Weber range- the DeVries-Rose to Weber transition point occurs at a higher illuminance with increasing frequency. A further linear range - in which sensitivity increases with unit slope as illuminance increases - can also be observed before the DeVriesRose range when low spatial frequency gratings flicker at high temporal rates (Kelly, 1972), but all the data considered in this paper were collected with gratings flickering at only $1 \mathrm{~Hz}$, where this linear range is not observed.

Contrary to this summary description, García-Pérez and Peli (1997) presented results of a literature review indicating (a) that a decreasing range exists past the Weber range at low frequencies, with a significant presence also at intermediate frequencies in some subjects, and (b) that the increase in sensitivity over the nominal DeVries-Rose range seems to depart significantly from the square-root law. As discussed by García-Pérez and Peli, departures from DeVriesRose behavior (i.e., a slope of 0.5 in $\log$-log coordinates) are clearly apparent in many empirical data bearing on this issue, leading us to question the validity of the DeVriesRose law for sine-wave gratings.

This paper analyzes empirical constraints from the shape of the contrast sensitivity function (CSF) at several illuminance levels and from the relationship between illuminance and visual acuity, showing that the DeVriesRose to Weber transition with sine-wave gratings can only hold at very low spatial frequencies.

\section{Sensitivity as a Function of Spatial Frequency and Illuminance}

Several attempts have been made to describe mathematically the dependence of sine-wave contrast sensitivity on spatial frequency and illuminance simultaneously (e.g., Daly, 1993; Rovamo, Mustonen, \& Näsänen, 1994). Figure 1a plots the function proposed by Rovamo et al. From this function, cross-sectional profiles at several illuminance levels (see the curves drawn on the right projection plane) have the characteristic shape described by empirical CSFs: Sensitivity decreases with decreasing illuminance, and the CSF peaks at a lower frequency and has a lower cutoff as illuminance decreases (compare with, e.g., DeValois, Morgan, \& Snodderly, 1974; van Meeteren \& Vos, 1972). Also, orthogonal cross-sections of the same surface (see the curves drawn on the left projection plane) have a shape that accommodates DeVries-Rose and Weber's laws, with the transition point also shifting towards higher illuminance with increasing frequency (compare with, e.g., Hess, 1990; Mustonen, Rovamo, \& Näsänen, 1993). Yet, this function (as well as that proposed by Daly, 1993) carries with it an incorrect relationship between acuity and illuminance (see the thick line on the base of the plot), as it suggests that the acuity limit increases without discontinuities as illuminance increases. Quite on the contrary, all available empirical data from man and primate (Cavonius \& Robbins, 1973; Hendley, 1948; Hess \& Nordby, 1986b; Hetch \& Mintz, 1939; Shlaer, 1937; Shlaer, Smith, \& Chase, 1942; van de Grind, Koenderink, \& van Doorn, 2000) indicate that this relationship has two branches and a point of discontinuity which is usually interpreted as indicating the transition from scotopic to photopic vision. The remainder of this section explores whether a sensitivity surface may exist that satisfies these three constraints, namely, cross-sectional profiles like those in the right and left projection planes of Figure $1 \mathrm{a}$ and a two-branch relationship between acuity and illuminance instead of the smooth curve in Figure 1a.

We start our exploration with recourse to available data from a single subject (see the thick curves in Figure 1b). These curves represent fits to data from Figure 1 of Hess and Nordby (1986b) and Figure 6 of Hess and Nordby (1986a), which come from the same normal subject. The empirical CSF was obtained at a reportedly optimal illuminance of 2000 scotopic td (optimal in that sensitivity did not increase significantly at higher illuminance levels) and the empirical acuity limit was obtained by determining the highest frequency that could be resolved at a $100 \%$ contrast at each illuminance. The curves were fitted as described in the Appendix. Then, these curves represent empirical constraints on the sensitivity surface for a normal subject who, if he/she is representative of the population, should show the characteristics imposed by any general law that applies to the illuminance-frequency sensitivity surface. The surface in Figure 1b was drawn according to DeVries-Rose and Weber constraints: At each frequency and starting at the minimal illuminance for visibility of that frequency (which is beyond the lower bound of the plot at low frequencies), sensitivity was made to increase with a slope of 0.5 up to the illuminance at which the ceiling CSF was reached, and then continued with a slope of 0 from that point on. Quite clearly, slopes of 0.5 fall short of reaching the ceiling CSF for frequencies above about $1 \mathrm{c} / \mathrm{deg}$. Then, DeVries-Rose and Weber behaviors are incompatible with these empirical data except at low spatial frequencies: Slopes should have to be larger than 0.5 at other frequencies in order to join the acuity limit and the ceiling CSF.

Figure 1c shows the results of relaxing the requirement that slopes are 0.5 at illuminance levels below the Weber range, and at each frequency the minimal illuminance for visibility has simply been linearly connected to the maximal sensitivity at frequencies where the DeVries-Rose constraint 
would not do. Yet, those linear increases do not solve a problem that was also apparent in Figure 1b, namely, linear increases have the side effect of mapping the discontinuity of the acuity line onto the CSFs (see the profiles on the right projection plane in Figure 1c). Although this characteristic was reported by Patel (1966, his Figure 1) for three subjects, this result does not seem to have been replicated since. In any case, these linear increases require a slope larger than 0.5 and, then, they disobey the DeVries-Rose law.
The only possibility, then, is that sensitivity at each frequency increases nonlinearly with illuminance in a way that the discontinuity of the acuity line does not map onto CSFs. Not all curvilinear relations produce this characteristic, but Figure 1d shows a plausible case. Note that any smooth CSF surface must have nonlinear cross-sectional profiles along the illuminance axis whose average slope is larger than 0.5 at high frequencies (see the curves on the left projection plane in Figure 1d).
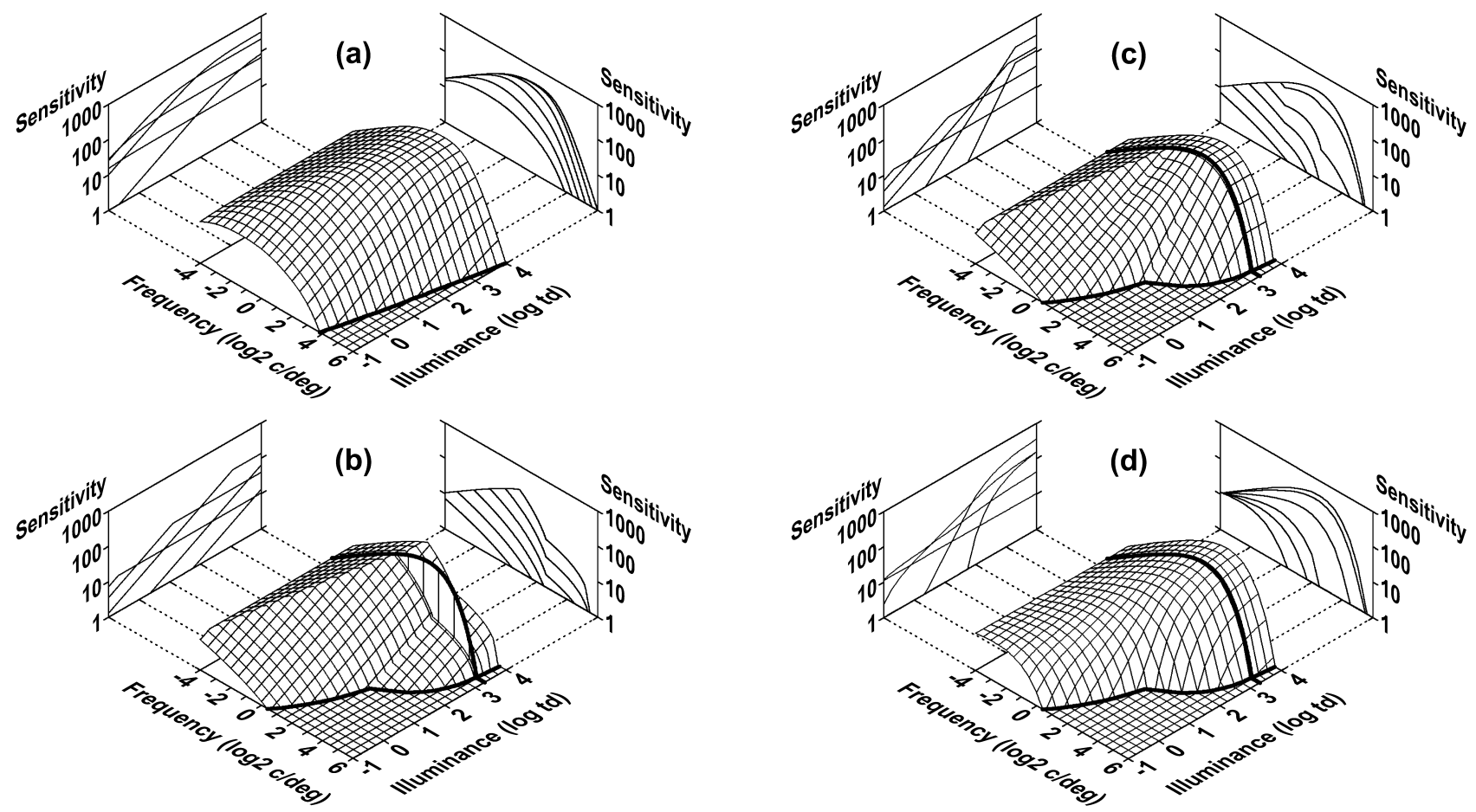

Figure 1. Contrast sensitivity surface as a function of spatial frequency and retinal illuminance under four sets of constraints. The projection plane on the right of each panel contains cross-sectional profiles of the surface at the six illuminance levels indicated with tick marks on the illuminance axis (i.e., at $-1,0,1,2,3$, and $4 \log$ td), thus revealing the implied shape of the CSF at those illuminance levels. The projection plane on the left contains cross-sectional profiles at the six frequencies indicated by labelled tick marks on the frequency axis (i.e., at -4, -2, 0, 2, 4, and $6 \log _{2} \mathrm{c} / \mathrm{deg}$ ), thus revealing the implied variation of the shape of the sensitivity versus illuminance (SVI) curve at those frequencies. Note that only five of these cross-sections can be seen in the left projection plane, because the cross-section at the highest frequency always lies at the base of the plot. (a) Sensitivity surface proposed by Rovamo et al. (1994) for gratings with a fixed area of $37.1 \mathrm{deg}^{2}$. The thick line on the base of the plot indicates the implied relationship between visual acuity (defined as the highest-frequency grating that can be resolved at a $100 \%$ contrast) and illuminance. (b) Sensitivity surface constrained to satisfy the empirical acuity versus illuminance (AVI) curve shown as a thick line on the base of the plot (from Figure 1 of Hess \& Nordby, 1986b), the empirical ceiling CSF shown as a thick line on the surface at an illuminance of 2000 scotopic td (from Figure 6 of Hess \& Nordby, 1986a), and the requirement that, at all frequencies, SVI curves increase with a slope of 0.5 until they reach the ceiling CSF. Note that these three constraints cannot be met simultaneously, as the ceiling CSF can only be reached at frequencies below $1 \mathrm{c} / \mathrm{deg}$. (c) Surface resulting from allowing SVI curves to increase with a slope such that, at all frequencies, the AVI curve and ceiling CSF connect through linear (or bilinear) segments. Although a surface that meets this less restrictive requirement exists, the implied CSFs at various illuminance levels (see the curves on the right projection plane) have discontinuities and bumps that empirical CSFs do not show. (d) Surface satisfying the requirements that CSFs are smooth at all illuminance levels (see the curves on the right projection plane) and their cutoff frequencies agree with the AVI curve. SVI curves (see the curves on the left projection plane) adhere to the DeVries-Rose to Weber transition only at very low spatial frequencies, but they are curvilinear with an average slope larger than 0.5 at other frequencies. This latter characteristic agrees indeed with the shape of most empirical SVI curves (see García-Pérez \& Peli, 1997). 


\section{Conclusion}

Given the empirical constraints provided by (a) the shape of the acuity versus illuminance curve and (b) the shape of the high-illuminance CSF, the DeVries-Rose law can only hold with sine-wave gratings of low spatial frequency. Yet, at low frequencies, empirical data indicate that there is a further range of decreasing sensitivity beyond the Weber range (see García-Pérez \& Peli, 1997), and this decreasing range is also observed at higher frequencies in some subjects (García-Pérez \& Peli, 1999). At intermediate and high frequencies, the increase in sensitivity with illuminance cannot be linear, and the average slope of this nonlinear increase must often be much larger than 0.5 .

The presence of DeVries-Rose and Weber ranges has been well documented at threshold and above threshold when the stimulus is a small spot that is flashed briefly (Aguilar \& Stiles, 1954; Barlow, 1957; Brown \& Rudd, 1998; Rose, 1948), and quantitative explanations or models for their occurrence have been put forward (DeVries, 1943; Rudd, 1996; Rudd \& Brown, 1996, 1997). When stimuli are sine-wave gratings, the DeVries-Rose law seems to be more dogma than established fact (see García-Pérez \& Peli, 1997). Although there is an appealing argument to expect DeVries-Rose and Weber ranges (see Rovamo, Näsänen, \& Mustonen, 1997), empirically, these ranges are only distinctly observed at low spatial frequencies. The source of the relationship between sensitivity to sinewave gratings and retinal illuminance seems to require a new theoretical justification.

\section{References}

Aguilar, M., \& Stiles, W.S. (1954). Saturation of the rod mechanism of the retina at high levels of stimulation. Optica Acta, 1, 5965.

Barlow, H.B. (1957). Increment thresholds at low intensities considered as signal noise discriminations. Journal of Physiology, 136, 469-488.

Brown, L.G., \& Rudd, M.E. (1998). Evidence for a noise gain control mechanism in human vision. Vision Research, 38, 19251933.

Cavonius, C.R., \& Robbins, D.O. (1973). Relationships between luminance and visual acuity in the rhesus monkey. Journal of Physiology, 232, 239-246.

Daly, S. (1993). The visible differences predictor: An algorithm for the assessment of image fidelity. In A.B. Watson (Ed.), Digital images and human vision (pp. 179-206). Cambridge, MA: MIT Press.

DeValois, R.L., Morgan, H., \& Snodderly, D.M. (1974). Psychophysical studies of monkey vision-III. Spatial luminance contrast sensitivity tests of macaque and human observers. Vision Research, 14, 75-81.
DeVries, H. (1943). The quantum character of light and its bearing upon the threshold of vision, the differential sensitivity and the visual acuity of the eye. Physica, 10, 553564.

García-Pérez, M.A., \& Peli, E. (1997). The transition from DeVriesRose to Weber's laws: Comments on Rovamo, Mustonen and Näsänen (1995). Vision Research, 37, 2573-2576.

García-Pérez, M.A., \& Peli, E. (1999). Lack of covariation of the effects of luminance and eccentricity on contrast sensitivity. Optometry and Vision Science, 76, 1-5.

Graham, N.V.S. (1989). Visual pattern analyzers. New York: Oxford University Press.

Hendley, C.D. (1948). The relation between visual acuity and brightness discrimination. Journal of General Physiology, 31, 433-457.

Hess, R.F. (1990). The Edridge-Green Lecture. Vision at low light levels: Role of spatial, temporal and contrast filters. Ophthalmic and Physiological Optics, 10, 351-359.

Hess, R.F., \& Nordby, K. (1986a). Spatial and temporal limits of vision in the achromat. Journal of Physiology, 371, 365385.

Hess, R.F., \& Nordby, K. (1986b). Spatial and temporal properties of human rod vision in the achromat. Journal of Physiology, 371, 387-406.

Hetch, S., \& Mintz, E.U. (1939). The visibility of single lines at various illuminations and the retinal basis of visual resolution. Journal of General Physiology, 22, 593-611.

Kelly, D.H. (1972). Adaptation effects on spatio-temporal sinewave thresholds. Vision Research, 12, 89-101.

Kelly, D.H. (1975). Spatial frequency selectivity in the retina. Vision Research, 15, 665-672.

Mustonen, J., Rovamo, J., \& Näsänen, R. (1993). The effects of grating area and spatial frequency on contrast sensitivity as a function of light level. Vision Research, 33, 20652072.

Patel, A.S. (1966). Spatial resolution by the human visual system. The effect of mean retinal illuminance. Journal of the Optical Society of America, 56, 689-694.

Rose, A. (1948). The sensitivity performance of the human eye on an absolute scale. Journal of the Optical Society of America, 38, 196-208.

Rovamo, J., Mustonen, J., \& Näsänen, R. (1994). Modelling contrast sensitivity as a function of retinal illuminance and grating area. Vision Research, 34, 1301-1314.

Rovamo, J., Näsänen, R., \& Mustonen, J. (1997). Transition from DeVries-Rose to Weber's law: Reply to García-Pérez and Peli (1997). Vision Research, 37, 2576-2578.

Rudd, M.E. (1996). A neural timing model of visual threshold. Journal of Mathematical Psychology, 40, 1-29.

Rudd, M.E., \& Brown, L.G. (1996). A model of Weber and noise gain control in the retina of the toad Bufo marinus. Vision Research, 37, 2433-2453.

Rudd, M.E., \& Brown, L.G. (1997). Stochastic retinal mechanisms of light adaptation and gain control. Spatial Vision, 10, 125148. 
Shapley, R., \& Enroth-Cugell, C. (1984). Visual adaptation and retinal gain controls. Progress in Retinal Research, 3, 263346.

Shlaer, S. (1937). The relation between visual acuity and illumination. Journal of General Physiology, 21, 165188.

Shlaer, S., Smith, E.L., \& Chase, A.M. (1942). Visual acuity and illumination in different spectral regions. Journal of General Physiology, 25, 553-569. van de Grind, W.A., Koenderink, J.J., \& van Doorn, A.J. (2000). Motion detection from photopic to low scotopic luminance levels. Vision Research, 40, 187-199.

van Meeteren, A., \& Vos, J.J. (1972). Resolution and contrast sensitivity at low luminances. Vision Research, 12, 825-833.

Received January 13, 2005 Revision received March 31, 2005 Accepted April 7, 2005 


\section{Appendix}

Figure 1 in Hess and Nordby (1986b) and Figure 6 in Hess and Nordby (1986a) were digitally scanned at a resolution of 600 dots per inch and the digital versions of these figures were used to extract the coordinates of the data points plotted on them. The empirical data in Figure 1 of Hess and Nordby (1986b) were described by the function

$$
\operatorname{CSF}(x)=188 x^{0.82} \exp [-0.25 x]
$$

where $x$ is spatial frequency. This mathematical form for the CSF was proposed by Kelly (1975) and the parameters in Equation (A1) were determined by eye yielding the fit shown in Figure 2a. Objective criteria for parameter estimation (e.g., least squares methods) might have yielded different parameter values, but the shape of the resultant function would not have been much different.

Similarly, the empirical data in Figure 6 of Hess and Nordby (1986a) were described by the function

$$
\operatorname{AVI}(x)= \begin{cases}0.1\left|\log \frac{x}{13}\right|^{-4.7} & \text { if } x<6 \\ 0.000592\left|\log \frac{x}{50}\right|^{-2.9} & \text { if } x \geq 6\end{cases}
$$

where $x$ is again spatial frequency $(x \leq 50)$. For mathematical convenience, Equation (A2) expresses luminance as a function of acuity (and not the other way around) and its parameters were also determined by eye yielding the fit shown in Figure $2 \mathrm{~b}$. Note that data points to fit this function were only available for illuminances above about $-2 \log$ td. Any extrapolated region below that illuminance level is, then, suspect. Nevertheless, the extrapolation is conservative in the sense that the resultant AVI curve does not threaten the validity of the DeVries-Rose to Weber transition in that region.

Although the fit of each function to the applicable empirical data is not excellent, the approximation is sufficiently good for our purposes here. As is clear in Figures $1 \mathrm{~b}$ and $1 \mathrm{c}$, alternative expressions that are only minimally different to better accommodate the empirical data will not have any major effect on the main conclusion that these two empirical functions cannot render a smooth contrast sensitivity surface that satisfies the DeVries-Rose to Weber transition.

(a) Contrast sensitivity function

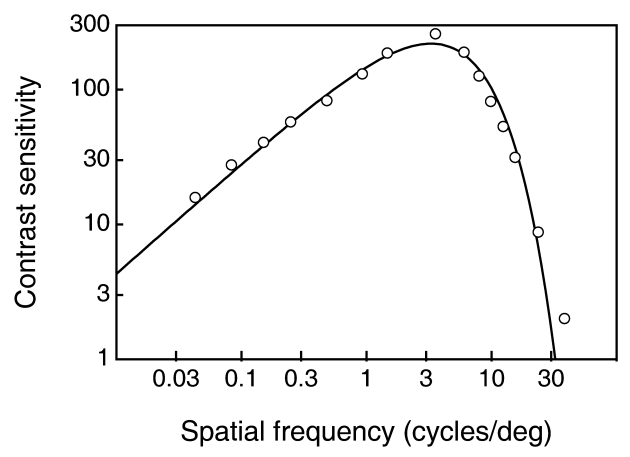

(b) Acuity versus illuminance curve

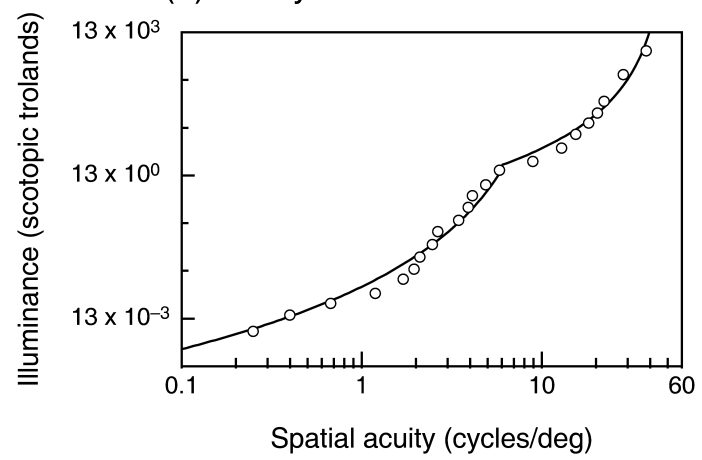

Figure 2. Data from Hess and Nordby (1986a, 1986b) and fitted curves describing the shape of the contrast sensitivity function (a) and the shape of the acuity versus illuminance relation (b). 